\title{
THE RAINFALL PROBABILITY ANALYSIS OF MAPALANA AND ITS APPLICATION TO AGRICULTURAL PRODUCTION OF THE AREA
}

\author{
K. D. N. WEERASINGHE \\ Department of Agronomy; Faculty of Agriculture, University of Rubuna, Mapalana, \\ Kamburupitiya, Sri Lanka.
}

(Date of receipt : 06 February 1989)

(Date of acceptance.: 09 August 1989)

\begin{abstract}
Absuractr Daily rainfall of the Mapalana Meteorological Station for 35 consecutive years were analysed for the Markov chain Probabilities for weekly rainfall and the rainfall availability of the location is assessed in relation to rice agronomy for both Yala and Maha seasons. It was revealed that the rainfall probability of $>10 \mathrm{~mm}$ at 75\% probability level and the Moisture Availability Index (MAI) of $>0.5$ as good indicators to select the cropping cycles of both seasons. The crop establishment program of Mapalana in the $\mathrm{Yala}_{2}$ and Maha seasons has to be commenced around 16th April and 10th September respectively. It appeared that the availability of rains during first weeks of April (1st to 15 th of April) has an impact on the success of the Yala program. The consecutive dry weeks which could be experienced in Octobet may delay the crop establishment program of Maha season till 41 st week in 5 out of 10 years.
\end{abstract}

\section{Introduction}

The quantity of rainfall received over a period of time at any location provides a general picture on its sufficiency to meet crop needs. But in tropical regions in particular it has been demonstrated that mean monthly rainfall, even when derived from a large number of years, is at best an unreliable guide to the variation in rainfall.

The arithmetic mean that is usually calculated directly from rainfall figures does not take in to account the inherent skewness of the raw data that results from a large amount of the rain falling in heavy tropical downpours thereby raising the level of the mean much above the normal amount of rainfall received or expected. 5

Moreover the recommendations based on mean monthly averages may sometimes be hazardous. ${ }^{4}$ Thus it has been suggested to consider the week as the unit of time in the tropics where the rainfall is showery and highly freakish in intensity, amount and distribution. ${ }^{2}$.

The concept of estimating probabilities with respect to a given amount of rainfall is extremely useful for agricultural operational planning.

In a growing season of a given crop, decisions have to be taken many times based on the probability of receiving certain amount of rainfall during a given week. ${ }^{8}$ The initial and conditional probability approach suggested by Robertson ${ }^{6}$ and Virmani ${ }^{8}$ would be a relatively good method for rainfall 
analysis, especially in the regions where rainfall is erratic or where short dry periods can be expected within the wet season.

The objective of the present analysis is to assess the rainfall distribution pattern in Mapalana in the Matara district where the research farm of the University of Ruhuna is located. A possibility for agroclimatological data analysis using moisture availability Index (MAI) according to Hargreaves $^{1}$ and probability. assessment by Markov chain procedure is discussed. The analytical procedure has a particular interest for the future agroclimatological data analysis in the Nilwala down-stream where an intensive land reclamaticn work has been commenced under the Nilwala flood protection Scheme.

\section{Materials and Methods}

Daily rainfa!l data of the Mapalana meteorological station, University of Ruhuna, for 35 consecutive years $(1950-1985)$ were used for the analysis. The Markov Chain probabilities for weekly rainfall of $>10,>20,>30$ and $>40 \mathrm{~mm}$ of rain were carried out. The probability of rainfall occurence at monthly, and weekly intervals at 50\%, 75\%, and $90 \%$ levels were assessed using the incomplete gamma distribution function.

A statistical package program developed by Virmani, Sivakumar, Reddi, ${ }^{9}$ ICRISAT, India was used for the analysis.

Initial probabilities of the rainfall in a wet week $p(W)$, conditional probabilities of a wet week following a wet week $p(W / W)$, and of a wet week following a diy $\mathrm{y}$ (W/D) were analysed.

Climatological indices suggested by Hargreaves ${ }^{1}$ and the method of Cocheme and Franquin, are used to assess the climate of the location. Runoff was estimated using the "W.ATBAL" model. Daily Rainfall, Evapotranspiration and the Field capacity of the soil were the inputs of the model.

\section{Results and Discussion:}

Mapalana is located in the agro-ecological region lowcountry wet zone (WL2). The mean zir temperature of the location is fairly uniform at around $28^{\circ} \mathrm{C}$ throughout the year. The relative humidity is usually lower in February and March (Figure 1). The average relative humidity of the location is around $73 \%$. The annual pan evaporation is $1560 \mathrm{~mm}$.

The soils of the area are red yellow podsolic in the upper part of the catens and low humic gley soils at the bottom. Soils are generally more than one meter deep and water-holding capacity of the soil is around $250 \mathrm{~mm}$ per meter depth. ${ }^{10}$

The monthly rainfall statistics for Mapalana during 1950-1985 are given in Table 1. Mean annual rainfall was $2354 \mathrm{~mm}$. The rainfall variation in the annual cycle was low (Cy 17\%). 


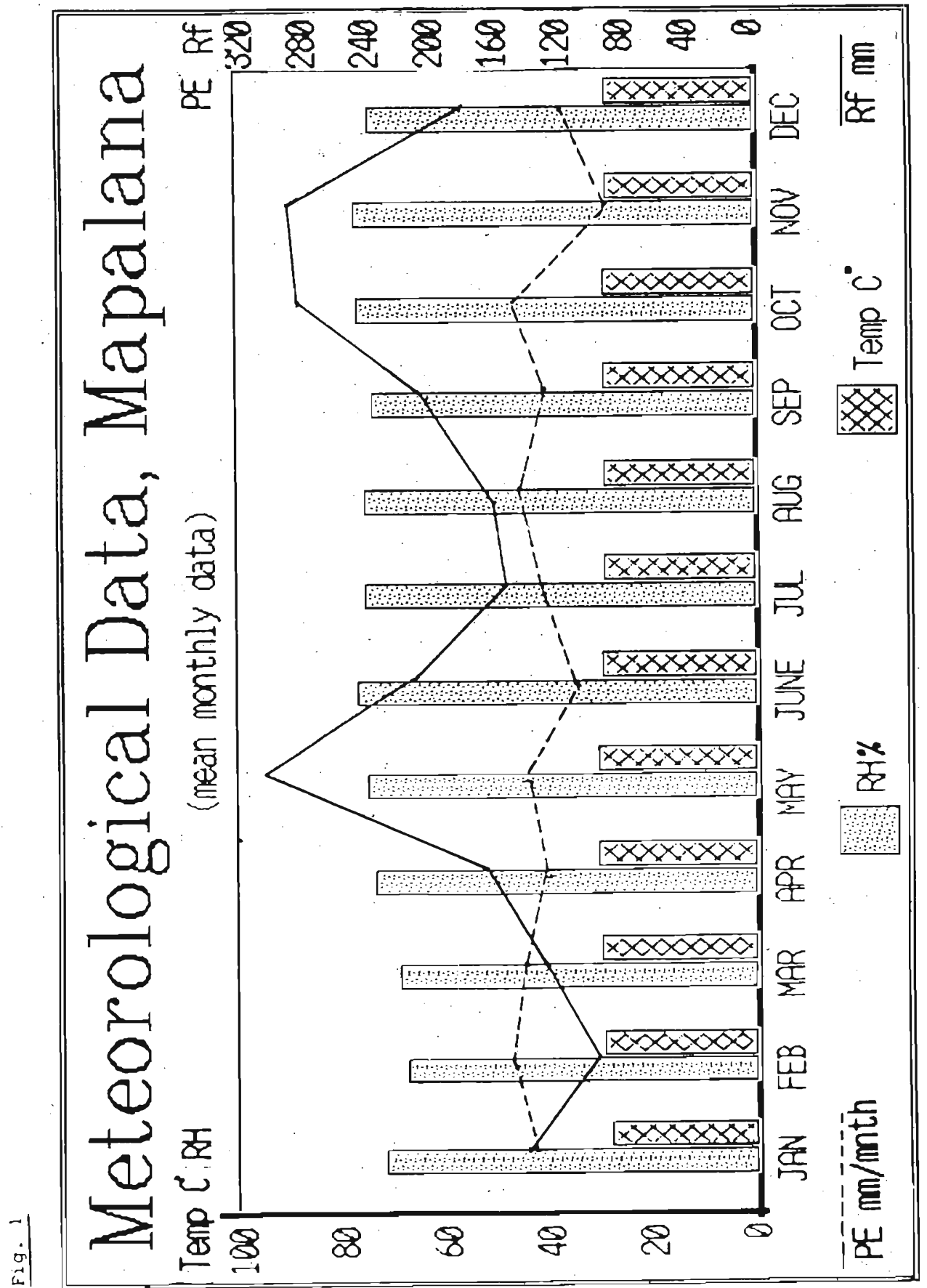




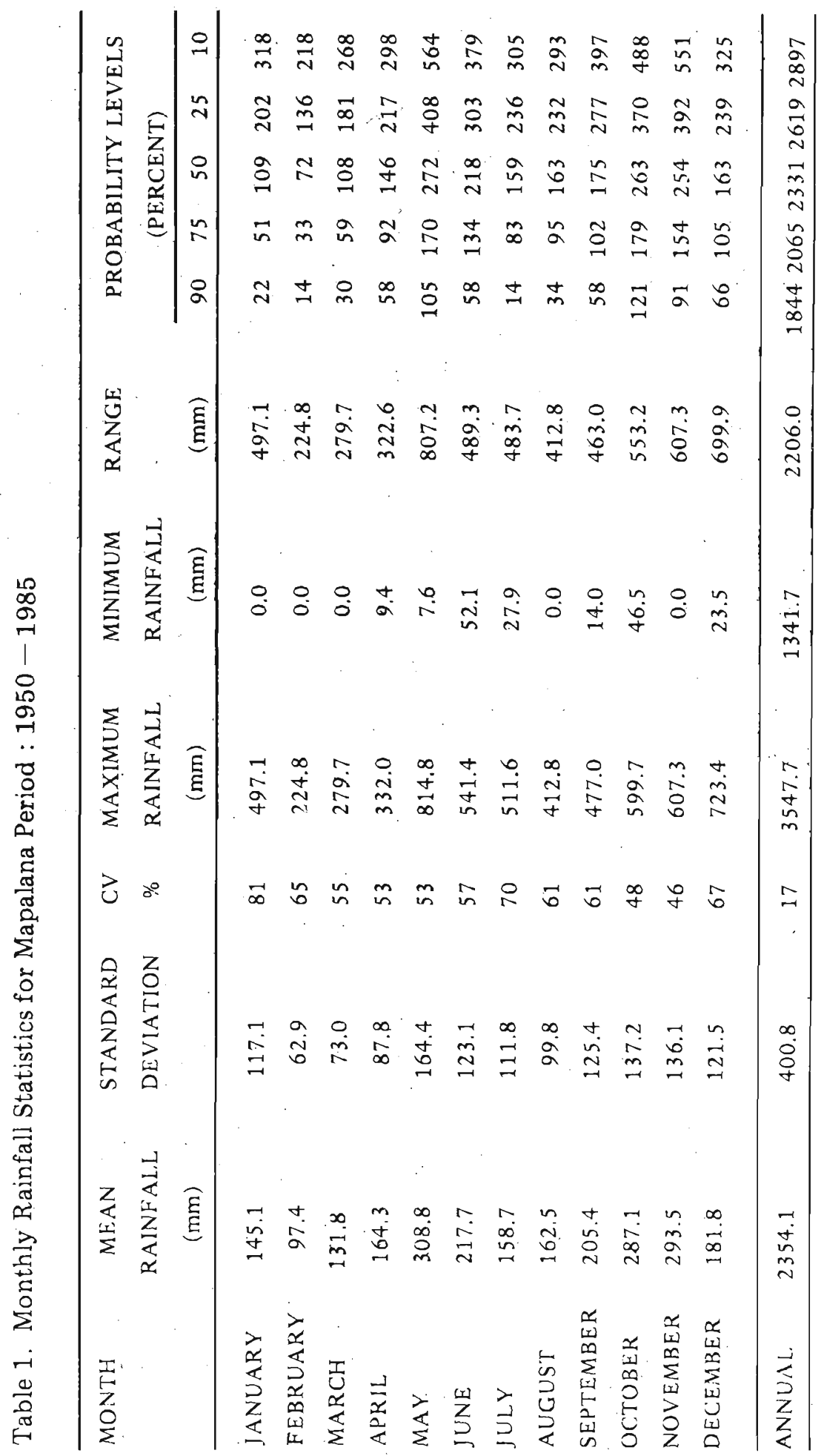


February is the driest month where an average of only $97.4 \mathrm{~mm}$ of rain could be expected. The average minimum rainfall of the location was $1342 \mathrm{~mm}$.

In Mapalana where temperature is not generally a limiting factor, the duration of the crop season depends on rainfall. Therefore farmers traditionally adapt their cropping practices to the prevailing precipitation distribution over the year.

Criteria for wet month for rice would be a month with more than $200 \mathrm{~mm}$ of rainfall which is considered as the minimum requirement for rainfed rice. ${ }^{3}$ Nevertheless water requirement for dry land crops are satisfied if the monthly precipitation is at least $92 \mathrm{~mm}$.

The criteria proposed by IRRI, and adapted by $\mathrm{FAO}^{4}$ state that monthly precipitation should be at least $200 \mathrm{~mm}$ for three consecutive wet months to allow a cultivation of a crop of bunded wetland rice.

It is clear for Mapalana (Table 1) that there are only two wet months in Yala (May and June) with over $200 \mathrm{~mm}$ of rain. But the Maha season has three consecutive wet months during September to November. Thus according to Oldeman, ${ }^{4}$ Yala at Mapalana could not considered to be suitable for rice cultivation without providing supplementary irrigation.

A more detailed picture of the moisture availability of the location could be observed when the probability of rain in weekly intervals is assessed.

The weekly distribution of rainfall in the annual cycle and the initial probabilities of the weekly rainfall of $>10$ and $>20 \mathrm{~mm}$ are given in Figure 2. Figure 3 represents the weekly rainfall at different probability levels. 


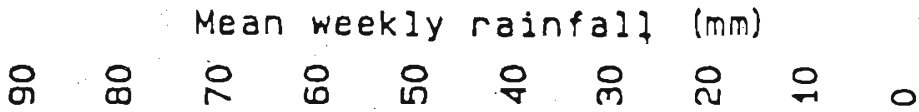

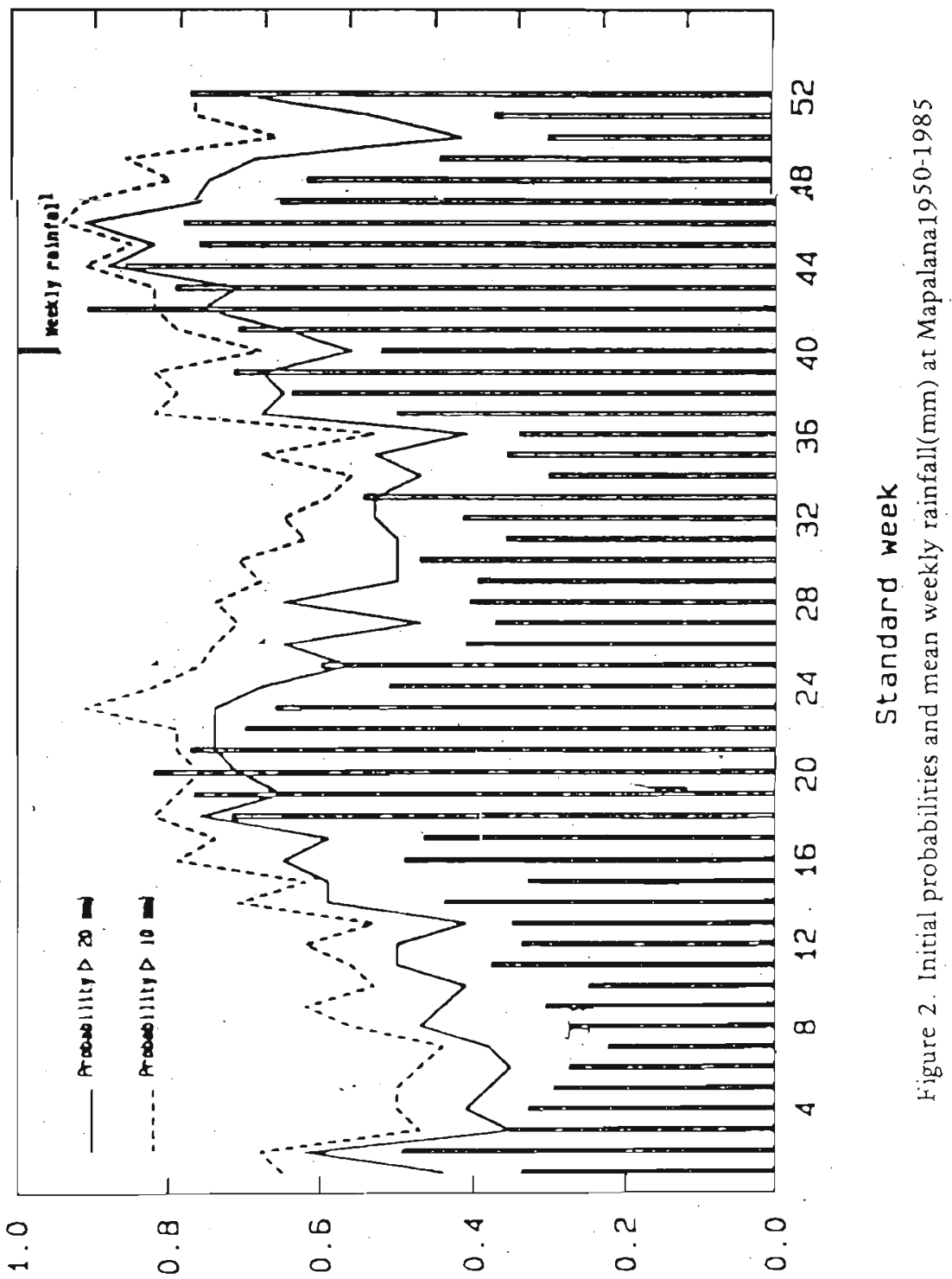

Probability 


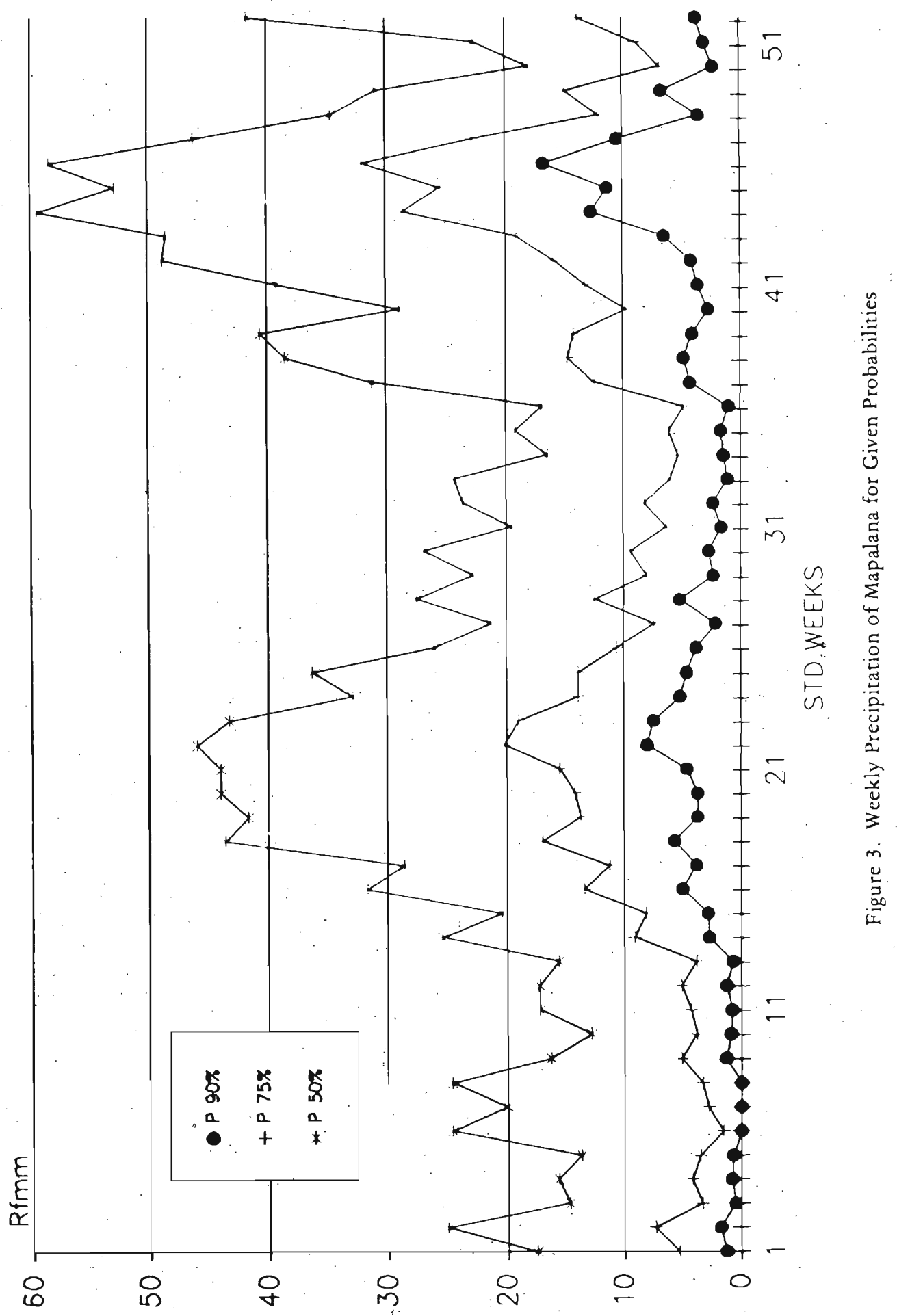


The rainfall distribution pattern exhibits a very distinct bimodal pattern. Probability of receiving $>10 \mathrm{~mm}$ of rain during the 1 st to $16 \mathrm{th}$ meteorological weeks is low, but from 16 th to 26 th and 37 th to 49 th weeks, the probability exceeds the level of $75 \%$.

The weekly rainfall of $>10 \mathrm{~mm}$ at $75 \%$ probability would be a sufficient level to satisfy the moisture requirement of the crops. Thus the precipitation of 16 th to 26 th and 37 th to 49 th weeks are adequate for the crop in 3 out of 4 years. The total rainfall received during these two periods is 149 and $235 \mathrm{~mm}$. This is the water availability of the Yala and Maha seasons at the $75 \%$ expectancy.

It is evident that the crop establishment program of the Yala in Mapalana should commence around 16th of April which falls with the 16th meteorological week. Analogically the 37 th week would be the ideal period to commence the crop establishment program for Maha season. But the commencement of Maha crop depends on the availability of rains for land preparation in late August and early September.

A $20 \mathrm{~mm}$ of rain at a $50 \%$ probability could be expected during 14 th to $33 \mathrm{rd}$ and 37 th to $52 \mathrm{nd}$ weeks in the two seasons (Figure 3). Apparently this is a good indicator to demarcate the onset and the end of the rainy seasons.

The probability of July rainfall drops after the 28 th week, but the chances to prevail dry weather in July and August compare to February will be low (Figure 2). The rain in this period may often affect the harvesting program.

It appears that the rainfall in 14 th -15 th weeks is more important in relation to Yala season. If sufficient rainfall for land preparation is received within this period the rainfall probability till the 25 th meteorological week would be adequate for the crop.

The rainfall adequacy to meet the potential evapotranspiration (PE) gives a better understanding on climatic water balance. Thus it would be more useful to consider the MAI values on a weekly basis in order to observe a more clear picture on the cropping cycles. According to Hargreaves the value of MAI $>0.34$ could be considered as the lower value for dryland crops. ${ }^{1}$

The MAI values exceed the lower threshold value of 0.34 in all the rainy months of Yala and Maha seasons (Figure 4). The data for the length, of the rainy seasons show that there are 119 days in Yala (14th to 30th weeks) and 112 days in Maha (38th to 52nd weeks) with MAI of $>0.34$. The average MAI of the Maha would be $49 \%$ high compared to the Yala season. 
During 1st to 13 th weeks (1st January to 2 nd April) and 31 st to 36th weeks (31st July to 10th September), MAI, values are below the lower threshold value.

The growing period within the season would be demarcated when the MAI will exceed the value of 0.5 . There are 11 weeks ( 16 th to 26 th weeks) in Yala and the 13 weeks (37th to 49 th weeks) in Maha with MAI $>0.5$. Nevertheless MAI during 40th and 41st weeks are low. Thus, the moisture availability in the first half of October in some years may not satisfy the total water requirement of the crop whereby delaying the sowing date till late October.

MAI in November (44th to 48 th weeks) is $>1.00$, which indicates that water in excess and soil may need good drainage. The high water availability in this period would be sufficient enough to meet the moisture requirement of the crop in the latter part of the Maha season.

The runoff of the location estimated by the WATBAL model (Figure 4) indicates that the percentage runoff in November would be much higher. The runoff is low in February-March but it increases with the rainfall in the rest of the year. High runoff in November may often cause the crop damage if the drainage is not adequate.

It appears that the MAI of $>0.5$ and the rainfall limit of $>10 \mathrm{~mm}$ at $75 \%$ expectancy as good indicators to demarcate the cropping periods of the Yala and Maha seasons for Mapalana. The periods demarcated agree with the farmers experience in the location.

In regions where often dry spells may exist, it is important to know the probability of having dry periods during the growing season. If the dry period coincides with a sensitive phenological phase this could damage the crop development. Once the crop is planted the water requirement is fairly continuous, and hence the conditional probabilities of occurence of rainfall is important.

In case of the initial probabilities the frequency of occurence of rainfall in a particular week is not related to the following week, but the conditional probability takes in to account the predetermined condition of rainfall in the previous week. The conditional probabilities of rainfall where wet week followed by a wet week (P W/W) and a wet week followed by a dry week at different rainfall limits are given in Figure 6. 


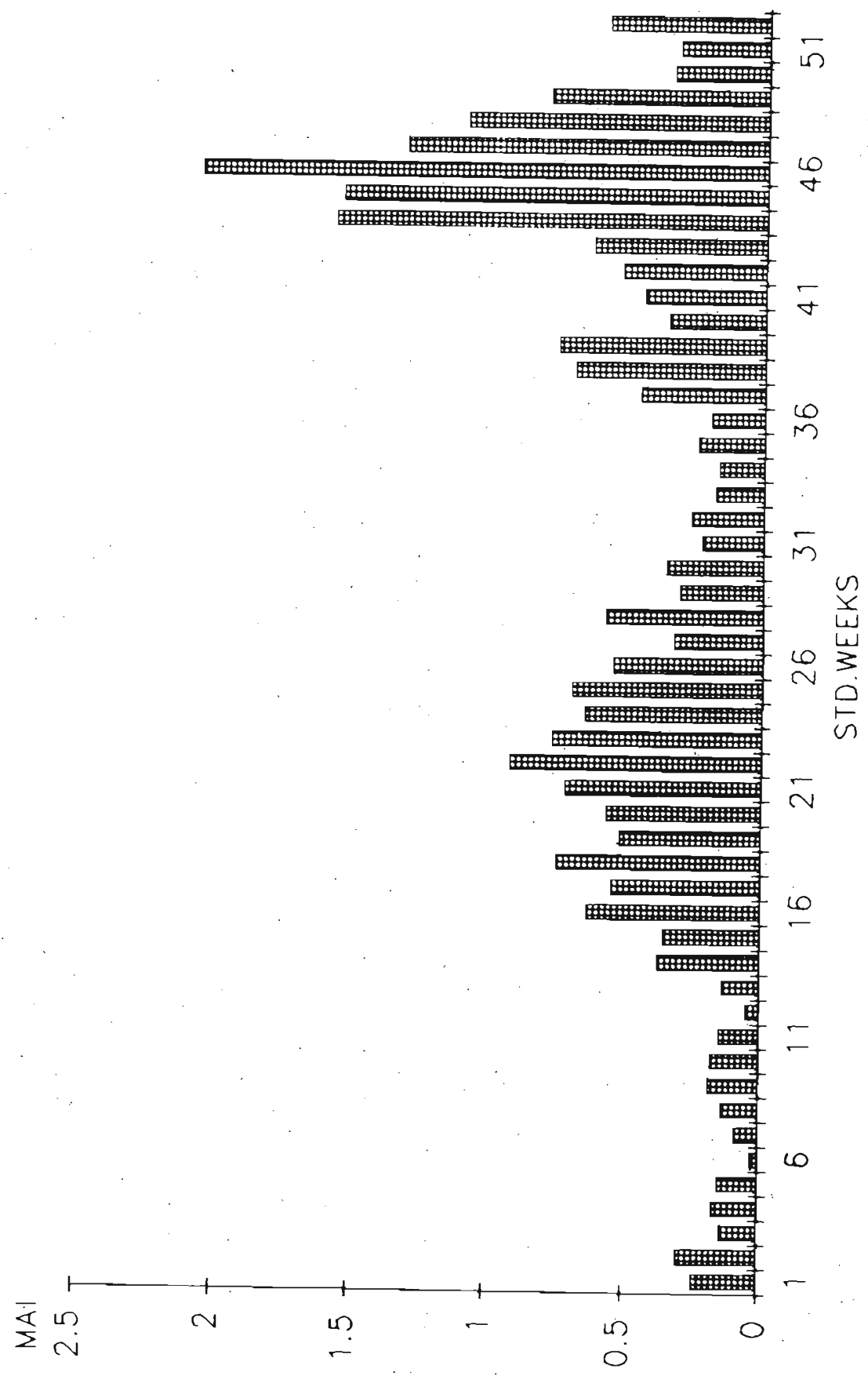




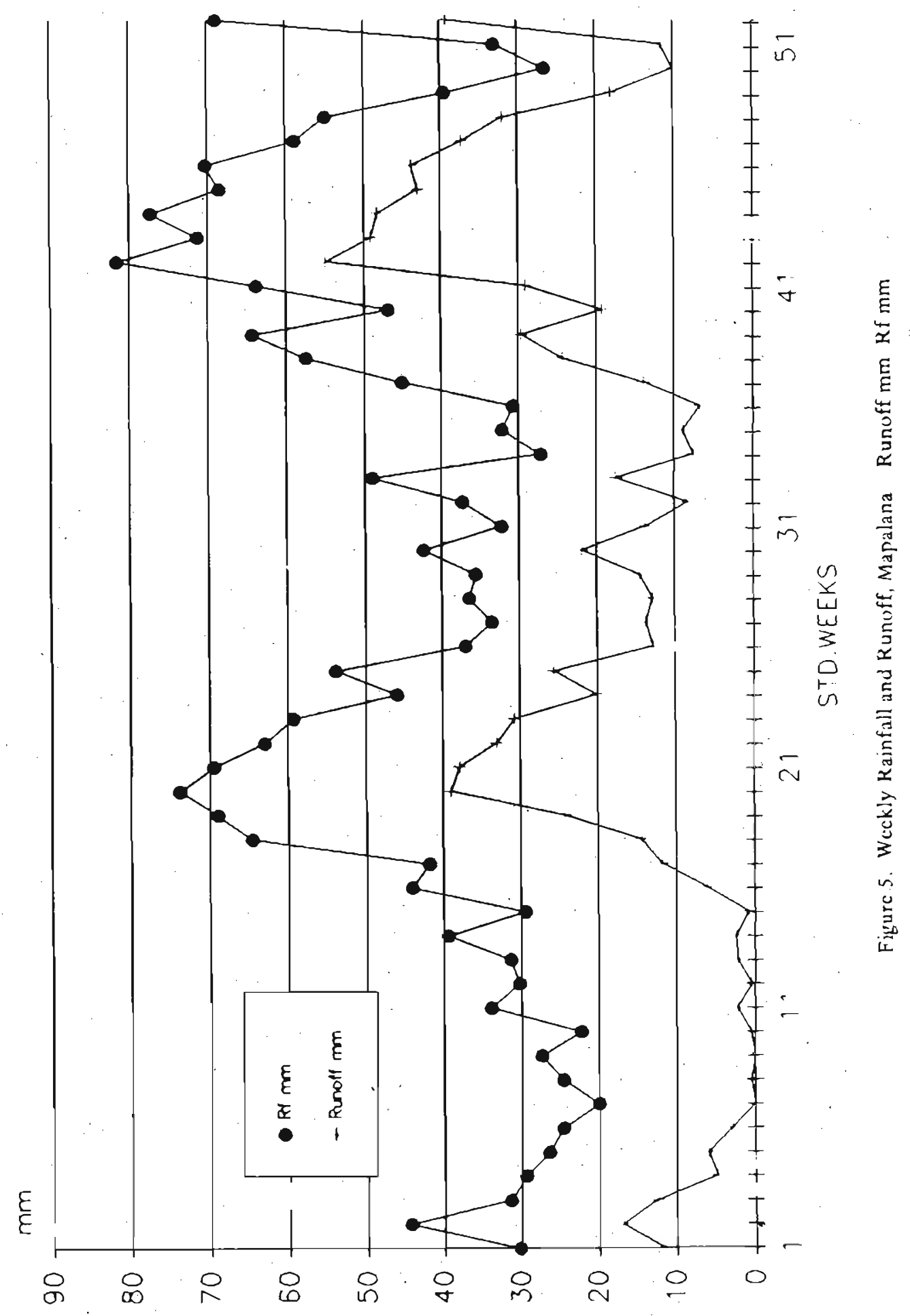




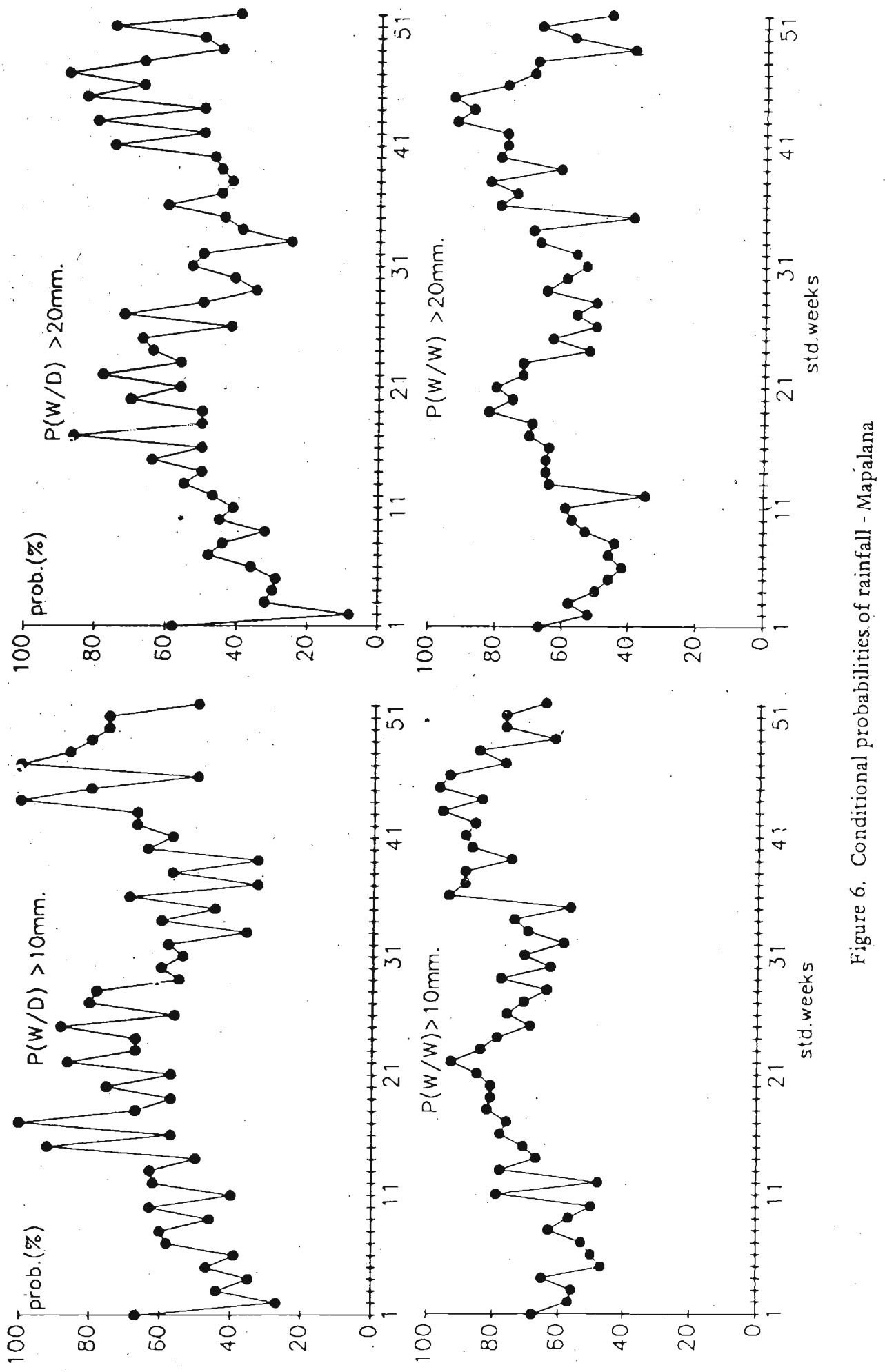


It appears that the 15 th week has a better chance to receive $>10 \mathrm{~mm}$, of rain even if the rain was not experienced in the previous week. Analogically the 17 th week has a higher probability to receive even $>20 \mathrm{~mm}$ of rain following a dry week. The probability to receive $>10 \mathrm{~mm}$ of rain following a dry week on 19th, 23 rd and 24 th weeks are less than $75 \%$. These weeks appeared to be the driest weeks of Yala in dry years where the supplementary irrigation would be required.

In general, the amount of rainfall received is low in the Yala season. Hence the period available for land preparation is short (14th to 16 th weeks) The rice ( in the area) is generally broadcast sown, but the introduction of transplanting with improved ploughing technology may help to minimize the length of the presowing period. Here the photoperiod insensitive short duration varieties (90-105 days), are needed.

September and October (37th to 43rd weeks) seem to be most critical for the Maha season in dry years. If the dryness prevailed in early September the chances to receive adequate rain till end of October is low. Thus in dry years, the probability to receive Maha rains till. 29th of October is less than $75 \%$. This is often the experience of the location where farmers have to delay the crop establishment program till late October. It appears that onset of monsoon may be delayed till late October in 5 out of 10 years.

\section{Acknowledgement}

The author gratefully acknowledges the assistance of many members of the staff of the Resource Management Program, ICRISAT, in respect to this paper. Special mention must be made of Dr. S. M. Virmani, and Dr. Piera Singh for their valuable instructions and assistance.

Assistance offered by the Director of the Meteorological Department, and the Assistant Director, Mr. B. D. Amaradasa to use the rainfall files of the Meteorological Department is gratefully acknowledged.

Thanks are due to Dr. J. L. Sabatier, "Hydraulics program", IRAT, France, who extended his cooperation to complete this work.

\section{References}

1. HARGREAVES et. al. (1985) A crop water evaluation manual for India. The International Irrigation Centre, Utah State University, Loghan, Utah, U.S.A.

2. KRISHNAN, A. (1980) Agroclimatic classification methods and their application to India. Climatic Classification. A Consultants meeting, ICRISAT. 59-119.

3. OLDEMAN, L.R. (1980) The Ägroclimatic classification of Rice growing environments in Indonesia. Proc. Symp. Agroclimatology of the rice crop. IRRI, 47-57.

4. OLDEMAN, L.R. \& FRERE, M. (1982) A Study of the Agro-Climatology of the Humid 
tropics of South Bast Asia. FAO/UNESCO/WMO Inter Agency project on Agro-Climatology. Technical note 179 , WMO, Geneva.

5. PANABOKKE, C.R. \& WALGAMA, A. (1974) The application of rainfall confidence limits to crop water requirement in dry Zone Agriculture in Sri Lanka. J. Natn. Sci Coun. Sri Lanka 2(2): 85-113.

6. ROBERTSON, G.W. (1976) Dry and wet spells. Tun. Razak Agric. Res. Centre. Sungh, Tekam, Malaysia project field report;Agrometereology A-6 15.

7. SAKAR, R.P. \& BISWAS, B.C. (1980) Agroclimatic classification for assessment of crop potential and its application to dry farming tracts of India. Climatic classification. A consultants meeting, ICRISAT, India, 89-119.

8. VIRMANI, S.M. (1976) The Agricultural Climate of the Hyderabad Region in relation to crop planning. A sample analysis. ICRISAT, Hyderabad, India. pp. 54.

9. VIRMANI, S.M., SIVAKUMAR, M.V.K. \& REDDY, S.J. (1982) Rainfall probability estimate for selected locations of semi Arid-India. Researcb Bulletin 1, ICRISAT, INDIA.

10. WEERASINGHE, K.D.N. \& ALWIS, P.L.A.G. (1985) Physical properties of the Red yellow podsolic soils under rubber, coconut and cinnamon cultivation in the Mapalana research farm. J..Robana, 1, 55-58.

11. WEERASINGHE, K.D.N. \& KATULANDA, W. (1988) Evapotranspiration requirement of rice at Mapalana in the wetzone of southern Sri Lanka. J. Natn. Sci Coun Sri Lanka. 16(1): 115-124. 